\title{
Fluid and fuel intake during exercise
}

\author{
EDWARD F. COYLE \\ The Human Performance Laboratory, Department of Kinesiology and Health Education, The University of Texas at \\ Austin, Austin, TX 78712, USA
}

Accepted 7 August 2003

\begin{abstract}
The amounts of water, carbohydrate and salt that athletes are advised to ingest during exercise are based upon their effectiveness in attenuating both fatigue as well as illness due to hyperthermia, dehydration or hyperhydration. When possible, fluid should be ingested at rates that most closely match sweating rate. When that is not possible or practical or sufficiently ergogenic, some athletes might tolerate body water losses amounting to $2 \%$ of body weight without significant risk to physical well-being or performance when the environment is cold (e.g. $5-10^{\circ} \mathrm{C}$ ) or temperate (e.g. $21-22^{\circ} \mathrm{C}$ ). However, when exercising in a hot environment $\left(>30^{\circ} \mathrm{C}\right.$ ), dehydration by $2 \%$ of body weight impairs absolute power production and predisposes individuals to heat injury. Fluid should not be ingested at rates in excess of sweating rate and thus body water and weight should not increase during exercise. Fatigue can be reduced by adding carbohydrate to the fluids consumed so that $30-60 \mathrm{~g}$ of rapidly absorbed carbohydrate are ingested throughout each hour of an athletic event. Furthermore, sodium should be included in fluids consumed during exercise lasting longer than $2 \mathrm{~h}$ or by individuals during any event that stimulates heavy sodium loss (more than 3-4 g of sodium). Athletes do not benefit by ingesting glycerol, amino acids or alleged precursors of neurotransmitter. Ingestion of other substances during exercise, with the possible exception of caffeine, is discouraged. Athletes will benefit the most by tailoring their individual needs for water, carbohydrate and salt to the specific challenges of their sport, especially considering the environment's impact on sweating and heat stress.
\end{abstract}

Keywords: carbohydrate, dehydration, fatigue, gastrointestinal function, hyperthermia, sodium.

\section{Introduction}

When athletes exercise during training or while competing, it is clear that they sometimes benefit by ingesting various mixtures of water, carbohydrate and electrolytes (Convertino et al., 1996; Casa, 2000). The benefits can be expressed through improved performance and/or reduced physiological stress, on an athlete's cardiovascular, central nervous and muscular systems. Although ample scientific evidence exists to support the general theory for encouraging athletes to consume water, carbohydrate and electrolytes during exercise, the practical recommendations for optimally applying these general theories is not simple. This is due to the quite varied nature of the physical stresses encountered during training and competition for a wide range of sports, as well as the unique rules of each sport regarding the allowance for fluid and fuel intake during competition. Furthermore, variations in the physical intensity, duration and environment, as well as indivi-

\footnotetext{
* e-mail: coyle@mail.utexas.edu
}

dual characteristics of a given athlete, might alter their optimal rate of water, carbohydrate and salt intake as well as the rate of gastrointestinal absorption and feelings of fullness. This task of developing consensus for general recommendations becomes less daunting when approached systematically through logical interpretation of the vast literature that has grown exponentially in the past two decades. It is also important to incorporate the experience of athletes recorded in carefully controlled 'field' studies or case reports, as this serves as a reality check regarding the conditions in which theories and laboratory findings can be applied directly to the overall welfare of athletes.

The aim of this article is to develop practical recommendations for fluid and fuel intake during exercise based upon interpretation of the scientific literature, with heavy reliance upon controlled laboratory studies as well as careful study of athletes in the field during training and competition. The focus of this review will be on identifying the conditions during which fluid and fuel intake positively or adversely affects either athletic performance or the physical well-being (i.e. acute and chronic health) of the individual athlete. 
Discussion of the physiological mechanisms mediating the performance effects will be limited to that which helps elucidate the practical application or refine the recommendation for fluid and fuel intake during exercise. Several excellent scientific review articles have already detailed the physiological mechanisms mediating reduced physiological strain during exercise by ingesting fluids, carbohydrate and electrolytes (Galloway and Maughan, 1998; Sawka and Coyle, 1999; Sawka and Montain, 2000; Cheuvront and Haymes, 2001; Cheuvront, 2001; Sawka et al., 2001). The last 40 years have seen dramatic shifts in both scientific thinking and popular practice regarding water, carbohydrate and salt intake during exercise. Here, I develop practical guidelines for the exercising athlete, based on modern science, recognizing lessons from past application and the limitations of our present understanding.

\section{Water or fluid intake}

A person's physiological drive for fluid intake during exercise is perceived through 'thirst mechanisms' and it has long been known that when given ad libitum access to fluid, and thus drink voluntarily, that these mechanisms compel people to drink at a rate that replaces approximately one-half of their fluid losses and at best two-thirds (Pitts and Consolazio, 1944; Hubbard et al., 1984). The concept that thirst during exercise does not drive people to take in fluid at the rate of fluid loss is termed 'voluntary dehydration'. In the 1960s, athletes were generally advised 'to drink only a little water during exercise' and to 'ignore their thirst' and to thus replace a small percentage of lost fluid. Furthermore, the scientific literature in the 1960s was interpreted to suggest that dehydration by less than $3-4 \%$ of body weight caused insignificant hyperthermia or impairment of physiological function and performance, although it was recognized that dehydration by more than $4 \%$ is dangerous to health (Wyndham and Strydom, 1969). This belief that dehydration by $3-4 \%$ was tolerable prevailed despite evidence to the contrary from carefully conducted studies around the time of the Second World War that had clearly shown that dehydration by less than 3-4\% during prolonged marching in the heat impaired performance and caused exhaustion and collapse (Pitts and Consolazio, 1944; Adolph, 1947; Ladell, 1955; Coyle and Montain, 1992a,b). The athletic community of this era appears to have remained unaware or unconvinced that the demands of marching were not unlike athletic endurance events, except, of course, for the speed and practical aspects of drinking while running compared with walking.

It was not until the 1970s that athletes were generally advised to ingest something more than just 'a little water' during exercise. In 1975, the American College of Sports Medicine (ACSM) published its first position stand entitled 'Prevention of heat injury during distance running'. In 1985, the ACSM published another position stand that advised runners to drink 100$200 \mathrm{ml}$ of fluid after every $2-3 \mathrm{~km}$. This recommendation acknowledged the large variation in ideal rate of fluid replacement among runners, with faster runners needing more and slower runners less fluid intake per hour. However, these broad recommendations did not provide sufficiently practical guidelines for drinking relative to thirst or sweating rate. At the extremes, this recommendation could be interpreted to suggest that it is permissible for slow runners $\left(10 \mathrm{~km} \cdot \mathrm{h}^{-1}\right)$ to drink only $330 \mathrm{ml} \cdot \mathrm{h}^{-1}$, whereas the fastest runners should drink as much $2000 \mathrm{ml} \cdot \mathrm{h}^{-1}$. The latter is a rate of fluid intake that is unrealistically high for most fast runners. However, this 1985 recommendation has theoretical merit in that it accurately set the limits for rates of sweating in slow and fast runners $\left(330-2000 \mathrm{ml} \cdot \mathrm{h}^{-1}\right)$. However, the ideal application of these broad guidelines would require the athlete to devise the schedule that meets not only their assumed need for fluid based on sweating rate, but also the rate of fluid replacement that is practical for them individually. It is unrealistic to expect that brief guidelines, which are naturally general, can be practised by all athletes in all sports under all conditions.

In its most recent position stand (Convertino et al., 1996), the ACSM recommended that: 'During exercise, athletes should start drinking early and at regular intervals in an attempt to consume fluids at a rate sufficient to replace all the water lost through sweating (body weight loss), or consume the maximal amount that can be tolerated'. This document further stated that 'individuals should be encouraged to consume the maximal amount of fluids during exercise that can be tolerated without gastrointestinal discomfort up to a rate equal to that lost from sweating'.

In an attempt to bring attention to the potential for developing hyponatraemia from drinking excessively large volumes of fluid during marathon running, Tim Noakes has been critical of the 1996 guidelines from ACSM (Noakes, 2003). Noakes quotes the 1996 guidelines for his statement that 'athletes are now advised to replace all the water lost through sweating (that is, loss of body weight), or consume the maximal amount that can be tolerated, or drink $600-1200 \mathrm{ml}$ per hour'. It is perplexing to the author of the current review how Dr. Noakes could interpret the 1996 guidelines from ACSM (Convertino et al., 1996) to suggest multiple recommendations, including the notion that athletes drink more fluid than is lost during exercise and therefore gain body weight. In an attempt to minimize current misinterpretation, misrepresenta- 
tion or confusion, and in agreement with common sense, athletes who begin exercise in the euhydrated state should not be advised to drink fluids at a rate causing them to gain both body weight and body water during prolonged exercise. Ingested fluid that is stored in the stomach may temporarily cause people to gain body weight above euhydrated levels, yet obviously the fluid volume of the intracellular and extracellular compartments will not increase until the ingested fluid moves into the intestines for absorption and distribution throughout the body. Nevertheless, it is important to point out that unrestricted drinking that causes initially euhydrated people to gain large amounts of body weight and body water should be discouraged. Methods to safeguard against significant body weight gains during exercise can range from simple recommendations to reducing access to fluids and finally to mandatory periodic weighing during an event. In 2000, the National Athletic Trainers Association published a position statement concluding that 'Fluid replacement should approximate sweat and urine losses and at least maintain hydration at less than $2 \%$ body weight reduction' (Casa, 2000).

With regard to water intake during exercise, the above paragraph summarizes the evolution of scientific consensus as well as the challenges in developing practical guidelines that give consideration to both health and athletic performance. As discussed below, it is our general premise that athletes be encouraged to drink fluids at a rate that matches sweating rate. However, those general guidelines must consider circumstances in which it is not practical to drink at such high rates. In some sports like running, the reductions in body weight due to dehydration have been theorized, yet not proven, to have less of a negative effect on performance because of assumed concomitant reductions in energy expenditure from dehydrationinduced reductions in body weight. However, these unproven theories must be tempered with the known negative effect of dehydration on health and performance. Furthermore, discussion should address the extent to which dehydration can be tolerated without heat illness depending upon variations in environment, individual state of 'fitness' and acclimation, as well as rates of heat production and heat dissipation. It would appear that the practical challenge is to better identify the specific athletic and environmental conditions in which exercising athletes should be advised to match fluid intake with sweating rate. On the other hand, during exercise in cool environments, some athletes might 'tolerate' a certain amount of dehydration, as discussed below. There presently seems to be general consensus in the literature that dehydration should not exceed $2 \%$ of body weight loss during most athletic events (Casa, 2000; Noakes and Martin, 2002). There- fore, from a practical perspective, the challenge now seems to be to identify sports, individuals and environments when $1 \%$ or $2 \%$ dehydration is 'tolerable', with little risk for heat illness and some potential performance benefits.

\section{Practical recommendations for fluid intake during exercise}

This practical challenge of identifying conditions of 'tolerable dehydration' must first recognize that dehydration reduces heat dissipation by reducing skin blood flow during exercise, usually resulting in an increased body core temperature (Coyle and Montain, 1992a,b; Gonzalez-Alonso et al., 1995). Furthermore, dehydration induces cardiovascular strain during exercise, best evidenced by a reduction in stroke volume. Using this reduced stroke volume as a reflection of cardiovascular strain during exercise, Gonzalez-Alonso (1998) has reported that dehydration without hyperthermia reduces stroke volume by $7-8 \%$ and that hyperthermia without dehydration also reduces stroke volume by $7-8 \%$. However, the combination of dehydration and hyperthermia elicits synergistic effects in reducing stroke volume by more than $20 \%$.

From a practical perspective, most athletes who experience significant dehydration will concomitantly experience a significant increase in core body temperature above that experienced during similar exercise conditions when euhydrated (Montain and Coyle, 1992; Gonzalez-Alonso et al., 1995, 1997; GonzalezAlonso, 1998). Readers should bear in mind that competitive athletes exercising at high intensity in sports such as running, cycling and soccer have high rates of heat production that require dissipation to the environment to prevent progressive heat storage and elevation of core temperature to above $39^{\circ} \mathrm{C}$. Given the rates of heat production averaging $800-1200 \mathrm{~W}$ in many athletic conditions, it is rare that dehydration would not cause hyperthermia. Hyperthermia was prevented with dehydration by $4 \%$ of body weight when exercising when the environmental temperature was lowered to $5^{\circ} \mathrm{C}$ and convective cooling was further increased by exposing the bare skin of the participants to wetting and high wind speeds (Gonzalez-Alonso, 1998). This is in line with the idea that some marathon runners competing in environmental temperatures as low as $7-18^{\circ} \mathrm{C}$ who become dehydrated by $3-5 \%$ of body weight can still experience core temperatures of 39.0-41. $7^{\circ} \mathrm{C}$ (Pugh et al., 1967; Maron et al., 1977; Maughan, 1984, 1985). Of course, there will be a wide range of core temperatures during exercise in a cold environment in runners with similar dehydration, based on how fast they are running towards the end of the race 
(Noakes et al., 1991a). However, the important point is that some athletes, often the fastest finishers, who experience significant dehydration, display core temperatures close to $40^{\circ} \mathrm{C}$ when running in cool environments of $7-18^{\circ} \mathrm{C}$ (Maron et al., 1977; Maughan, 1984, 1985). This agrees with the observation of GonzalezAlonso et al. (1998) that prevention of hyperthermia in athletes dehydrated by $4 \%$ of body weight is achieved only when very high rates of convective cooling are achieved through a cold environmental temperature $\left(5^{\circ} \mathrm{C}\right)$ and high wind speed. Given that athletic events are seldom contested in such conditions, it is logical to suggest that dehydration will most commonly elicit hyperthermia in athletes competing intensely. From this basis, the question of how much dehydration is acceptable must be answered relative to how much hyperthermia is acceptable, recognizing potential individual variability in the extent to which dehydration elicits negative effects such as hyperthermia.

Recent studies have found fatigue to occur in heatacclimated runners when core temperature reaches approximately $40^{\circ} \mathrm{C}$ and dehydration is not great (Gonzalez-Alonso et al., 1999b; Nielsen et al., 2001; Nielsen and Nybo, 2003). However, given that hyperthermia and dehydration are synergistic to fatigue, it must be recognized that dehydrated people are less tolerant of hyperthermia and they usually collapse or fatigue at core temperatures in the range of 38.5$39.5^{\circ} \mathrm{C}$ (Montain and Coyle, 1992; Sawka and Coyle, 1999; Cheuvront, 2001; Cheuvront and Haymes, 2001; Sawka et al., 2001).

\section{Effects of dehydration on cardiovascular strain, hyperthermia and muscle metabolism}

Dehydration appears to have a robust effect on cardiovascular strain as evidenced by the observation that for every $1 \%$ of body weight loss due to dehydration, heart rate increases by $5-8$ beats $\cdot \min ^{-1}$ and cardiac output declines significantly, while core temperature also increases by $0.2-0.3^{\circ} \mathrm{C}$ (Brown, 1947; Coyle and Montain, 1992a,b; Sawka and Coyle, 1999; Cheuvront, 2001; Cheuvront and Haymes, 2001; Sawka et al., 2001). As discussed below, dehydration during exercise reduces endurance performance through a number of interrelated mechanisms involving increased cardiovascular strain due to hyperthermia and reduced blood volume, as well as direct effects of hyperthermia on muscle metabolism and neurological function (Gonzalez-Alonso et al., 1995, 1997, 1998, 1999a,b, 2000; Gonzalez-Alonso, 1998; GonzalezAlonso and Calbet, 2003). Dehydration and hyperthermia have profound effects on reducing stroke volume and muscle blood flow, thus limiting oxygen delivery to exercising skeletal muscle. Hargreaves et al. (1996) observed that dehydration increases muscle glycogen use during continuous exercise, possibly as a result of increased core temperature, reduced oxygen delivery and/or increased catecholamines.

\section{Effects of dehydration on endurance performance}

As discussed by Cheuvront et al. (2003), studies examining endurance performance in temperate environments $\left(20-21^{\circ} \mathrm{C}\right)$ during exercise lasting less than 90 min have reported that dehydration by $1-2 \%$ of body weight has a statistically insignificant effect on performance (Robinson et al., 1995; McConell et al., 1999; Bachle et al., 2001). However, dehydration by $2 \%$ of body weight, which generally occurs during exercise lasting more than $90 \mathrm{~min}$, does appear to significantly impair endurance performance in environments of 20-21 $1^{\circ} \mathrm{C}$ (Cheuvront et al., 2003). Therefore, it would appear that athletes participating in endurance events lasting less than $90 \mathrm{~min}$ in temperate environments can generally tolerate dehydration by $1-2 \%$ of body weight without any significant impact upon performance. However, exercise lasting more than $90 \mathrm{~min}$ and with more than $2 \%$ dehydration appears to impair performance in temperate environments of $20-21^{\circ} \mathrm{C}$ (Fallowfield et al., 1996; McConell et al., 1997; Cheuvront et al., 2003).

In hot environments $\left(31-32^{\circ} \mathrm{C}\right)$, sweating rate is higher and thus $60 \mathrm{~min}$ of intense exercise typically elicits dehydration by approximately $2 \%$ of body weight. Exercise performance over approximately $60 \mathrm{~min}$ in a hot environment has been observed to be impaired by both Below et al. (1995) and Walsh et al. (1994) with dehydration amounting to $2 \%$ and $1.8 \%$, respectively. Therefore, dehydration by $2 \%$ of body weight during exercise in a hot environment $\left(31-32^{\circ} \mathrm{C}\right)$ clearly impairs endurance performance, but when exercise is performed in a temperate environment $\left(20-21^{\circ} \mathrm{C}\right)$, dehydration by $2 \%$ appears to have a lesser and insignificant effect on endurance performance. Collectively, these findings suggest that athletes are advised to attempt to offset dehydration as much as possible when exercising intensely in a hot environment $\left(31-32^{\circ} \mathrm{C}\right)$ for durations approaching $60 \mathrm{~min}$ and longer. When the environment is temperate $\left(20-21^{\circ} \mathrm{C}\right)$, athletes may be better able to tolerate $2 \%$ dehydration without significant performance decrement or risk of significantly added hyperthermia compared with exercise with full fluid replacement. In cold environments, dehydration by more than $2 \%$ may be tolerable. Figure 1 displays the concept that progressively greater dehydration may be tolerable and without significant performance decrement in endurancetrained athletes as the environment gets progressively cooler. A similar concept was proposed by Adolph et al. 


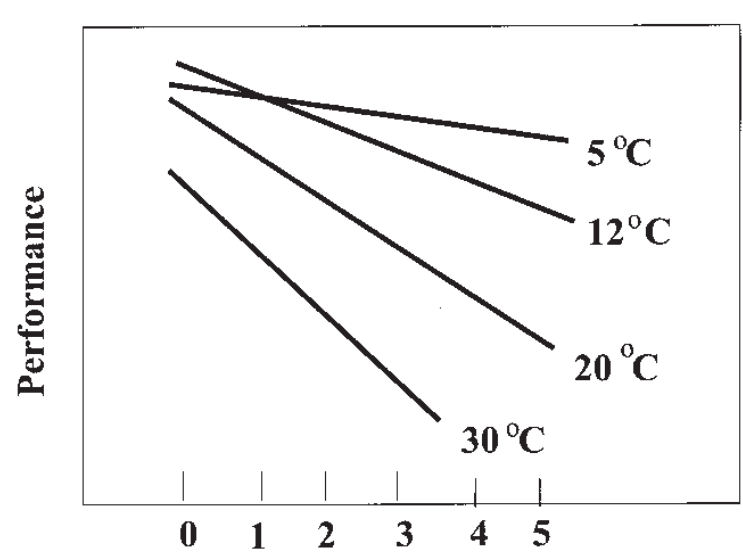

Dehydration (\% body weight loss)

Fig. 1. Theoretical effects of dehydration on endurance performance during prolonged exercise in environments that vary in temperature from 5 to $30^{\circ} \mathrm{C}$ (see text for discussion).

(1948) and discussed recently by Sawka and Montain (2000).

\section{Timing of fluid intake during exercise and practical issues regarding tolerable dehydration}

Montain and Coyle (1993) demonstrated that the benefits of ingesting 1.2 litres of fluid (when sweating rate was $1.21 \cdot \mathrm{h}^{-1}$ ) during $140 \mathrm{~min}$ of exercise in the heat required $40-60 \mathrm{~min}$ to be realized in terms of reduced heart rate and core temperature as well as improved blood volume and plasma osmolality. This agrees with the time-course with which that volume of ingested fluid would be distributed throughout the body after gastric emptying, intestinal absorption and osmotic flow (Noakes et al., 1991b; Schedl et al., 1994). Given this 40-60 min time period needed to realize the benefits of drinking fluids in a hot environment while sweating heavily, it becomes clear that benefits from fluid intake during events lasting less than 40-60 min will not be realized during exercise. Obviously, ingested fluid that has not been distributed throughout the body and which remains in the gastrointestinal tract will be of no benefit in terms of reducing cardiovascular or thermal strain during exercise. In another light, offsetting body weight loss by drinking fluids does not offset cellular dehydration until at least $40 \mathrm{~min}$ has passed, which is the time needed for the ingested fluid to function.

Appreciation of this time-course of fluid absorption and distribution helps reconcile practical issues about whether the tolerable level of dehydration during exercise in a hot environment is $2 \%$ body weight loss or less. From a cellular perspective (independent of fluid in the gut), no amount of dehydration can be tolerated without strain on the cardiovascular and thermoregulatory systems. This is best observed after $120 \mathrm{~min}$ of exercise in the heat $\left(33^{\circ} \mathrm{C}\right)$ with a fluid drinking schedule designed to minimize delay in fluid replacement to cells, by giving a large volume early in exercise followed by subsequent frequent feedings aimed at maintaining high gastric volumes and thus high emptying rate, yet a low gastric volume at the end of exercise (Montain and Coyle, 1992; GonzalezAlonso et al., 1995). Under these conditions, dehydration by $2.3 \%$ compared with only $1.1 \%$ of body weight elicited a significantly higher heart rate and core temperature (Montain and Coyle, 1992). Furthermore, when comparing dehydration ranging from 1 to $4 \%$ of body weight, it was clear that no amount of body weight reduction and dehydration was without negative physiological consequences after $120 \mathrm{~min}$ of exercise in the heat (Coyle and Montain, 1992a). This measurable and statistically significant effect of only a $1.2 \%$ body weight difference in true dehydration (i.e. 2.3 vs $1.1 \%$ ) amounts to approximately 1 litre or less of body water. Functionally, however, the benefit of this additional 1 litre of fluid replacement is realized only when it has had time to be absorbed and distributed throughout the body. Under these conditions, each 1 litre of fluid ingested to offset dehydration had the benefit of reducing core temperature by $0.3^{\circ} \mathrm{C}$ and lowering heart rate by 8 beats $\cdot \min ^{-1}$ while raising cardiac output $11 \cdot \min ^{-1}$ (Montain and Coyle, 1992).

During exercise in the heat $\left(33^{\circ} \mathrm{C}\right)$, therefore, dehydration by $1-2 \%$ of body weight will indeed increase core temperature and add significant cardiovascular strain (Montain and Coyle, 1992; Sawka and Coyle, 1999; Sawka and Montain, 2000; Sawka et al., 2001). Again, this is unlike exercise in a cold environment (Fig. 1). Yet, when exercising in the heat with a high sweat rate, it is not often possible for athletes to exercise with the large gastric volume needed to promote the high rates of gastrointestinal fluid absorption that are required to prevent cellular dehydration during exercise. For example, if an athlete finishes 90 min of exercise with no body weight loss but with 1.5 litres of fluid in the gastrointestinal tract, he or she would not be expected to display any physiological benefit of that 1.5 litres of fluid compared with a condition in which exogenous fluid is not present in the gastrointestinal tract. The only expected difference would be that he or she would weigh less (by the weight of 1.5 litres of fluid), amounting to a reduction in body weight of approximately $2 \%$. Therefore, it would appear that the additional 1.5 litres of fluid ingestion, which prevents body weight from declining $2 \%$, is not beneficial in terms of core temperature or cardiovascular strain. However, in this case, body 
weight would not be an accurate reflection of cellular hydration. Therefore, intelligent discussion of whether or not the tolerable level of dehydration is $0 \%$ or $1 \%$ or $2 \%$ of body weight loss must recognize the limitations of using whole-body weight as a measure of dehydration when fluid remains in the gut at the time when body weight is measured.

When sweating rate exceeds $11 \cdot \mathrm{h}^{-1}$, it becomes progressively more difficult to offset cellular dehydration in many individuals because this requires exercising with a gastric volume of approximately $0.6-1.0$ litre of fluid. The discomfort of that added volume and weight will not reduce physiological stress if it remains in the gut towards the end of the event and some individuals may not benefit by drinking the extra volume that ensures no body weight reduction at the end of exercise. Therefore, from a performance perspective, sometimes it may be advised to drink less than needed for full fluid replacement and finish with up to a $2 \%$ reduction in body weight provided that the drinking schedule is designed to minimize gut fluid volume towards the end of exercise. This is best achieved by drinking larger volumes early in exercise and continuing to ingest fluid throughout so that stomach volume is high with $40 \mathrm{~min}$ remaining and little fluid is ingested thereafter.

\section{What do fast marathon runners experience?}

In recent review articles, Cheuvront and colleagues (Cheuvront, 2001; Cheuvront and Haymes, 2001; Cheuvront et al., 2003) indicate that faster marathon runners tend to experience greater dehydration at the end of the marathon with values ranging from 2 to $8 \%$ body weight loss. However, they are careful to point out that this should not be interpreted to suggest any advantage of becoming dehydrated but rather that when running faster, the difficulty encountered in drinking fluids causes a progressively greater dehydration because of an increasing mismatch between fluid loss and replacement in most runners. Furthermore, Cheuvront and colleagues (Cheuvront, 2001; Cheuvront and Haymes, 2001; Cheuvront et al., 2003) point out that within the population of qualifiers for the US Olympic Trials in the marathon, that a weak relationship exists between level of dehydration and performance. The puzzling question in marathon running is how some runners perform so well despite final dehydration of 48\% of body weight (Wyndham and Strydom, 1969; Costill, 1972) and core temperatures in excess of $40^{\circ} \mathrm{C}$ (Pugh et al., 1967). One possibility is error in magnitude of true dehydration from the perspective that the marathon runners might have begun the race somewhat hyperhydrated at the time of pre-race body weight measurement.
Another possibility is that when running, reductions in body weight due to dehydration might lower the oxygen cost of movement. For example, if dehydration reduces body weight and the absolute oxygen cost of running by $4 \%$, yet absolute power output is reduced by less than $4 \%$, the power output per kilogram of body weight could theoretically be increased, although no direct data exist, to the author's knowledge, to confirm or refute this hypothesis. However, given the robust negative effect of dehydration-induced hyperthermia, this theoretical increase in performance potential (power per kilogram) can only be realized if the individual can tolerate hyperthermia when dehydrated. Bearing in mind that the combination of dehydration and hyperthermia act synergistically to impair cardiovascular function, such 'functional' dehydration is a gamble. Unfortunately, data are not available to calculate the ratio of risk of hyperthermia compared with the theoretical benefit of reduced energy expenditure as a result of reduced body weight from dehydration. Ideally, calculation of the risk-benefit ratio should be made with knowledge of the individual athlete under the specific exercise intensity and environmental conditions to identify when an individual might be best capable of surviving the clear negative effects of dehydration and hyperthermia to gain potential advantages of reduced oxygen cost.

\section{Practical application to marathon runners}

The question of optimal fluid replacement for marathon runners is not new. It has long been recognized that runners generally drink only $500 \mathrm{ml} \cdot \mathrm{h}^{-1}$ of fluid and thus allow themselves to dehydrate at rates of 500$1000 \mathrm{ml} \cdot \mathrm{h}^{-1}$. The performance question again boils down to whether the time lost as a result of drinking larger volumes will be compensated by the physiological benefits drinking produces and the faster running pace that might be achieved during the last half of the race. However, if the goal is safety, which means minimizing hyperthermia, there is no question that the closer that the rate of drinking can match the rate of dehydration, the better (Coyle and Montain, 1992a,b). Runners need to determine this for themselves, as there is much individual variability in the time lost when drinking larger fluid volumes both because of the methods of drinking on the run as well as the amount of gastric discomfort encountered due to a variety of individually unique factors, such as gastric emptying rate and how gastric anatomy interacts with running style and sensation of stomach fullness. This appears to be a case where one general recommendation will not be ideal for a significant number of runners, but it represents a starting point for them to begin the trialand-error process for themselves. 
Noakes and Martin (2002) recently advised that 'runners should aim to drink as needed between 400$800 \mathrm{ml}$ per hour, with the higher rates for the faster, heavier runners competing in warm environmental conditions and the lower rates for the slower runners/ walkers competing marathon races in cooler environmental conditions'. This is also a reasonable starting point from which individual runners should begin the trial-and-error process. It is likely that some fast runners will be able to drink more than $800 \mathrm{ml} \cdot \mathrm{h}^{-1}$, which may be especially beneficial in environments eliciting heavy sweating of $1000-1500 \mathrm{ml} \cdot \mathrm{h}^{-1}$. Therefore, individuals should attempt to drink $1000 \mathrm{ml} \cdot \mathrm{h}^{-1}$ or more during fast training runs so that they can best learn to meet their unique needs. Obviously, higher rates of fluid replacement are most important to individuals who experience more dehydration and who are more adversely affected by dehydration-induced hyperthermia. Furthermore, because of the running time lost in obtaining and drinking more fluid, recognizing individual variability in potential discomfort from stomach fullness must be considered. From a practical perspective, it is quite inefficient for runners to drink from open cups handed to them. Athletes and race organizers should devise better practical methods by which runners can drink larger volumes without slowing or having to carry fluid containers in their hands.

\section{Excessive fluid intake and hyponatraemia}

A serious although infrequent problem is the development of hyponatraemia, especially in runners and walkers who drink excessively large volumes of low sodium fluids throughout prolonged exercise (Noakes et al., 1985; Barr and Costill, 1989; Vrijens and Rehrer, 1999; Montain et al., 2001; O’Brien et al., 2001; Speedy et al., 2001). Fast drinking in these slow-moving individuals (4-6 hour marathon times) causes them to gain significant body water over the course of the marathon distance because fluid replacement is far in excess of sweating rate. Therefore, recommendations should always convey quantitative limits. For example, a very simple recommendation that might serve as a deterrent to hyponatraemia for slow runners, while not misguiding the faster runners, is that a marathon distance requires consumption of not more than 2-4 litres of fluid. Hyponatraemia is discussed further in the section on salt intake during exercise.

\section{Fluid intake and performance during sports and intermittent exercise}

Many sports such as basketball, ice hockey, soccer and tennis are contested over prolonged periods consisting of intermittent yet high-intensity exercise. The question is whether these athletes should attempt full fluid replacement compared with their typical practice of incurring dehydration of approximately $2 \%$ or more of body weight (Bangsbo et al., 1991; Maughan, 1991; Maughan et al., 1993; Bangsbo, 1994; Maughan and Leiper, 1994). The situation is not unlike marathon running in terms of whether there is an allowable level of dehydration relative to the environment and the individual athlete and the practical realities involved in drinking large volumes of fluid. Furthermore, successful performance in these sports involves more than energy expenditure and fatigue resistance, as winning also depends on cognitive function for decision making as well as proper execution of complex skills, making assessment of sport performance quite challenging.

Williams and colleagues have developed a shuttlerunning test (Loughborough Intermittent Shuttle Test) aimed at simulating the intense 'stop and go' nature of sports such as soccer (Nicholas et al., 2000). They have observed that fluid replacement prevents a reduction in soccer skill performance and mental concentration due to dehydration (McGregor et al., 1999b; Nicholas et al., 1999).

\section{Carbohydrate intake}

\section{Background with prolonged continuous exercise}

Although there was some evidence long ago that carbohydrate ingestion during exercise improved athletic performance, the discovery of the importance of muscle glycogen as a source of carbohydrate energy for athletes in the 1960s and 1970s (Bergstrom et al., 1967) appears to have obscured thinking until the 1980s regarding the potential energy contribution of ingested carbohydrate (Coyle et al., 1986; Coggan and Coyle, 1991; Hargreaves, 1996). For example, Costill and Miller (1980) emphasized the need for fluid intake during exercise but they did not recommend ingesting very much carbohydrate. This recommendation is understandable at that time, given that the physiological benefits of fluid replacement were beginning to be established, as reflected in the 1975 ACSM position stand, whereas the physiological benefits of carbohydrate ingestion for blood glucose supplementation as well as the physiological mechanisms explaining this benefit were yet to be firmly established (Hargreaves, 1996). In the 1980s, the observation that the addition of carbohydrate to water temporarily slowed gastric emptying rate was interpreted to suggest that fluid replacement solutions should not contain much carbohydrate (Coyle et al., 1978). It is now understood that the slight slowing of gastric emptying caused by solutions containing up to $8 \%$ carbohydrate is a relatively minor factor in fluid replacement rate 
compared with the large influence of increased fluid volume for increasing gastric emptying and fluid replacement rate (Maughan, 1991; Maughan and Noakes, 1991; Coyle and Montain, 1992a,b; Maughan et al., 1993). It was also thought, albeit mistakenly, that 'ingested glucose contributes very little to the total energy utilized during exercise' (Costill and Miller, 1980). Therefore, the prevailing recommendation in 1980 was that 'under conditions that threaten the endurance athlete with dehydration and hyperthermia, fluid replacement solutions should contain little sugar $(>25 \mathrm{~g} / \mathrm{L}$ or $>2.5 \%)$ and electrolytes' (Costill and Miller, 1980).

In the 1980s, it was established that ingested carbohydrate and blood glucose can indeed be oxidized at rates of approximately $1 \mathrm{~g} \cdot \mathrm{min}^{-1}$ and that this exogenous carbohydrate becomes the predominant source of carbohydrate energy late in a bout of prolonged continuous exercise (Convertino et al., 1996). Therefore, carbohydrate ingestion delays fatigue during prolonged cycling and running and it also improves the power output that can be maintained (Millard-Stafford, 1992; Millard-Stafford et al., 1995, 1997; Hargreaves, 1996). Therefore, as reviewed previously, it is generally recommended that endurance athletes ingest carbohydrate at a rate of $30-60 \mathrm{~g} \cdot \mathrm{h}^{-1}$ (Convertino et al., 1996; Casa, 2000). The carbohydrate can be in the form of glucose, sucrose, maltodextrins or some high glycaemic starches. Fructose intake should be limited to amounts that do not cause gastrointestinal discomfort (Convertino et al., 1996; Casa, 2000). This rate of carbohydrate ingestion can be met by drinking $600-1200 \mathrm{ml} \cdot \mathrm{h}^{-1}$ of solutions containing 4-8\% carbohydrates (4-8 g $100 \mathrm{ml}^{-1}$ ) (Rehrer et al., 1993; Rehrer, 1994; Convertino et al., 1996; Casa, 2000).

\section{Performance during short-term intermittent high-intensity bouts of exercise}

The benefits of carbohydrate ingestion during performance of high-intensity intermittent exercise attempted after at least $60 \mathrm{~min}$ of continuous

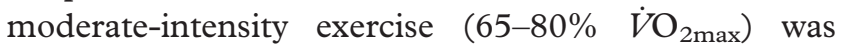
the focus of a study beginning in the late 1980s. Power measured over 5-15 min of high-intensity and predominantly aerobic exercise has generally been observed to be increased by ingesting carbohydrate (Murray et al., 1987, 1989; Coggan and Coyle, 1988; Mitchell et al., 1989; Sugiura and Kobayashi, 1998). In the 1996 ACSM position statement on 'Exercise and Fluid Replacement', it was concluded that 'During intense exercise lasting longer than $1 \mathrm{~h}$, it is recommended that carbohydrates be ingested at a rate of $30-60 \mathrm{~g} / \mathrm{h}$ to maintain oxidation of carbohydrates and delay fatigue' (Convertino et al., 1996).

During the past decade, attention has focused on determining if carbohydrate intake during sporting events such as soccer and tennis improves various indices of performance. As discussed below, carbohydrate ingestion appears frequently to benefit performance, as demonstrated in tests of 'shuttle-running' ability, which simulate the stop and start nature of many sports requiring bursts of speed and some fatigue resistance (Nicholas et al., 2000). The physiological mechanisms for this ergogenic effect of carbohydrate ingestion are unclear and have been theorized to involve more than simply skeletal muscle metabolism, implying a neuromuscular component. The challenge at the present time seems to be how to identify the types of physical activity and sporting scenarios for which carbohydrate ingestion is advisable, as well as identifying those circumstances in which such a recommendation is not effective or even counterproductive.

\section{Conditions in which carbohydrate ingestion during exercise does not appear to improve performance}

Performance or fatigue resistance can be governed by many physiological factors involving primarily the skeletal muscle, the cardiovascular system and the nervous system. It is to be expected that some primary causes of fatigue are not influenced by carbohydrate ingestion during exercise. For example, the negative effect of hyperthermia on performance of prolonged exercise in a hot environment $\left(33-35^{\circ} \mathrm{C}\right)$ does not appear to be lessened by carbohydrate ingestion (Febbraio et al., 1996a; Fritzsche et al., 2000). However, during exercise in a cool environment $\left(5^{\circ} \mathrm{C}\right)$ that is not limited by hyperthermia (Febbraio et al., 1996a), or when individuals drink fluids during exercise in a hot environment and do not become hyperthermic (Fritzsche et al., 2000), carbohydrate feedings indeed improve performance. Under conditions not eliciting hyperthermia, the factor most important for performance of prolonged and intense exercise appears to be maintaining carbohydrate availability and thus oxidation, especially from blood glucose oxidation as muscle glycogen concentration declines. This was better achieved by ingesting carbohydrate solutions of $7 \%$ than $14 \%$ (Febbraio et al., 1996a).

Another example of when carbohydrate ingestion during exercise would not be expected to improve performance is when fatigue is due to the accumulation of hydrogen ions in skeletal muscle (low muscle $\mathrm{pH}$ ), as occurs during a single bout of intense exercise performed continuously for 20-30 min. Exercise that is not sufficiently stressful to cause fatigue, as evidenced 
by reduced power production, or that does not require high effort to maintain power, as reflected for example by high levels of various stress hormones, would not be expected to benefit from carbohydrate ingestion. Furthermore, carbohydrate intake is not generally recommended during events that are completed in 30-45 min or less, performed either continuously or intermittently. Although this last point has not been extensively studied to date, it is an assumption based upon the practice of athletes competing in events lasting only 30-45 min. As discussed, carbohydrate ingestion does not appear to lessen fatigue due to hyperthermia or dehydration-induced hyperthermia, even when exercise is prolonged (1-3 h) (Febbraio et al., 1996a; Fritzsche et al., 2000). Thus, there does not appear to be any benefit of adding carbohydrate to fluid replacement solution under these conditions. Therefore, people who exercise at moderate intensity for less than $1 \mathrm{~h}$, and who do not experience fatigue, do not appear to benefit from carbohydrate ingestion during exercise. Yet ingesting 30-60 g carbohydrate $\cdot \mathrm{h}^{-1}$ does not appear to present a general physiological risk to people who do not experience gastrointestinal discomfort.

\section{Conditions in which carbohydrate ingestion improves performance through unexplained physiological mechanisms}

Carbohydrate ingestion during prolonged exercise can benefit performance if fatigue is due to inadequate carbohydrate energy from blood glucose (Coggan and Coyle, 1991; Febbraio et al., 1996b). This is one welldocumented physiological mechanism by which the ergogenic benefit of carbohydrate ingestion during exercise can be explained. However, carbohydrate ingestion has been observed to improve performance under conditions where fatigue is not clearly due to lack of aerobic or anaerobic carbohydrate energy. For example, when the duration of continuous exercise is extended to approximately $60 \mathrm{~min}$ and thus the intensity is $80-90 \% \quad \dot{V O}_{2 \max }$, carbohydrate ingestion during exercise has been shown to improve power output by $6 \%$ during the 50-60 min period (Below et al., 1995).

Other recent studies have also reported a performance benefit of carbohydrate feeding when the total duration of the performance bout is approximately $60 \mathrm{~min}$ or more. The total period of $60 \mathrm{~min}$ or more is broken up into shorter exercise durations, thereby simulating the demands of many sports (basketball, soccer, hockey) in which high-intensity exercise is interspersed with periods of recovery (Murray et al., 1987, 1989; Mitchell et al., 1989). Carbohydrate ingestion is ergogenic during 15-min bouts of intermittent 'shuttle running' performed several times (five times), as well as during repeated high-intensity intervals of $1 \mathrm{~min}$ duration (and $3 \mathrm{~min}$ recovery) (Nicholas et al., 1995; Davis et al., 1997, 1999, 2000a; McGregor et al., 1999; Welsh et al., 2002). Thus, the total duration of these work-rest bouts was over $60 \mathrm{~min}$.

The physiological mechanisms responsible for these performance benefits of carbohydrate ingestion are not clear and have been theorized to involve the central nervous system, skeletal muscle and/or the cardiovascular system. It is likely that carbohydrate feeding influences the interactions of all three of these systems, possibly through the actions of neurotransmitters, hormones and other peptides that are already known (e.g. insulin, catecholamines, serotonin) or are emerging as important (e.g. interleukin-6), or those substances which have yet to be discovered. Regardless, sufficient evidence is accumulating to recommend carbohydrate ingestion during continuous or intermittent exercise that lasts for $60 \mathrm{~min}$ or more and where fatigue is due to factors other than hyperthermia.

\section{Can carbohydrate ingestion during exercise be counterproductive?}

It is recommended that carbohydrate be ingested at a rate of $30-60 \mathrm{~g} \cdot \mathrm{h}^{-1}$ during exercise, recognizing that ingesting more does not increase oxidation rate yet ingesting more can produce gastrointestinal discomfort in many people (Rehrer et al., 1992; Wagenmakers et al., 1993). Therefore, carbohydrate feeding can be counterproductive when ingested in amounts $\left(>60-90 \mathrm{~g} \cdot \mathrm{h}^{-1}\right)$ or concentrations $(>7-8 \%)$ that are too large (Febbraio et al., 1996a; Galloway and Maughan, 2000). This is a common practical mistake among athletes that could be remedied by simple education.

A separate question is whether carbohydrate ingestion at $30-60 \mathrm{~g} \cdot \mathrm{h}^{-1}$ during exercise can impair performance when compared with no carbohydrate ingestion. It could have a negative effect if it produced gastrointestinal discomfort, a factor that is likely to vary from sport to sport and from athlete to athlete. Caution should also be used when recommending carbohydrate ingestion during events lasting approximately 15-45 min that require repeated bouts of intense exercise lasting several minutes followed by several minutes of rest. These events have the potential to elicit large swings in blood glucose and insulin concentration, thus requiring feeding plans that are specific to the varied intensity and time demands of the event. Those feeding schedules might be more than those described below, yet without data or experience to make more specific recommendations, all that can be done at present, besides recognizing these limitations, is to encourage systematic trial and error. 
From a practical perspective, the recommendation of ingesting $30-60 \mathrm{~g} \cdot \mathrm{h}^{-1}$ of carbohydrate during exercise should emphasize that this be accomplished by taking feedings every $10-30 \mathrm{~min}$, as allowed by the event. The goal of the feeding schedule should be to create a steady flow of carbohydrate from the gut into the bloodstream. In other words, if carbohydrate feeding is begun during an event, it should be continued throughout the event in a manner that allows for a steady flow of exogenous glucose into the blood with minimal gastrointestinal discomfort. It is especially inadvisable to give a large bolus of carbohydrate (more and 30-60 g) early in an event and then discontinue carbohydrate feeding. This practice will prime the body for glucose metabolism, and reduce fat oxidation, and then deprive the body of the fuel it has been primed to metabolize.

\section{Salt intake during exercise}

\section{Background}

Sodium chloride is the major salt lost in sweat, with sodium being the electrolyte most critical to performance and health. Sodium levels within the extracellular fluid, as reflected by plasma sodium concentration, should remain within a range of 130$160 \mathrm{mmol} \cdot 1^{-1}$ to keep cells, tissues and organs functioning with the proper volumes of fluid and thus optimal balance. A striking example of this imbalance is seen when a low serum sodium concentration (hyponatraemia below $130 \mathrm{mmol} \cdot \mathrm{1}^{-1}$ ) causes fluid movement into the brain, causing swelling with symptoms that can progress from feeling strange, to mental confusion, general weakness, collapse, seizure, coma and death. Because the sodium concentration in sweat is much lower than that of plasma, the primary cause of hyponatraemia is dilution of body water by drinking a large volume of low sodium-containing fluid over several hours, and it can be exacerbated by also losing large amounts of sodium in sweat (Vrijens and Rehrer, 1999; Montain et al., 2001; O'Brien et al., 2001; Rehrer, 2001).

Sodium lost in sweat can vary greatly among individuals, with concentrations ranging from 20 to $80 \mathrm{mmol} \cdot 1^{-1}$ (Maughan, 1991; Schedl et al., 1994). Heat acclimation generally reduces sodium losses by reducing sweat sodium concentration more than sweating rate is increased. However, it is becoming increasingly clear that some heat-acclimated athletes can still lose large amounts of sodium when sweating heavily for $2 \mathrm{~h}$ because of their individual, and probably genetic, trait of producing sweat very high in sodium. It is likely that excessive loss of sodium during exercise in these athletes might cause them to fatigue due to development of muscle weakness or cramps. Although it is difficult to study groups of these individuals due to the infrequency of 'muscle cramping', it would appear that provision of extra dietary salt before and during exercise is warranted in these athletes (Schedl et al., 1994; Eichner, 1998).

\section{Recommendations for sodium intake during prolonged exercise}

In most athletes exercising and sweating for $4-5 \mathrm{~h}$ with a sweat sodium concentration of less than $50 \mathrm{mmol} \cdot 1^{-1}$, the total sodium lost is less than $10 \%$ of total body stores (total stores are approximately $2500 \mathrm{mmol}$ or $58 \mathrm{~g}$ for a 70-kg person). These losses appear to be well tolerated by most people (Barr and Costill, 1989; Barr et al., 1991; Barr, 1999). On the other hand, the inclusion of sodium in fluid replacement drinks has some theoretical benefits, and the addition of sodium poses little or no risk. In fact, the addition of sodium in certain concentrations and types improves taste while also stimulating the osmotically dependent dipsogenic factors (thirst) that appear to increase voluntary drinking, thus minimizing involuntary dehydration (Wilk and Bar-Or, 1996; Wemple et al., 1997). Absorption of fluids that enter the intestines is more rapid when sodium is present and this has the potential to aid sugar absorption (Schedl et al., 1994). However, sufficient sodium is present in ingested fluid or water by the time it reaches the intestines for absorption, even when no sodium is ingested, due to the movement of endogenous body sodium into fluid within the gastrointestinal tract. Therefore, there is not presently a well-documented need to include sodium in fluid replacement drinks ingested during exercise, at least in terms of fluid and sugar absorption into the body (Rehrer et al., 1993; Hargreaves et al., 1994; Vrijens and Rehrer, 1999; Rehrer, 2001). Yet, given the potential for sodium to stimulate thirst and drinking and since it is lost in sweat, the potential logical benefits outweigh the low risk. Therefore, it is recommended that sodium $\left(20-40 \mathrm{mmol} \cdot \mathrm{l}^{-1}\right)$ be included in fluids ingested during exercise, especially when it is prolonged (longer than $1 \mathrm{~h}$ ). When exercise is performed for several hours, or when large amounts of sodium are lost in sweat, it is especially important for athletes to include sodium in fluid replacement solutions to minimize hyponatraemia. It is prudent to suggest that sodium be included in fluids consumed during exercise lasting more than $2 \mathrm{~h}$ or by individuals during any event that stimulates heavy sodium loss (more than 3-4 $\mathrm{g}$ of sodium).

\section{Intake of other electrolytes during exercise}

Compared with sodium and chloride, the concentration of other electrolytes in sweat is low. For example, the 
average concentrations are: potassium, $5 \mathrm{mmol} \cdot \mathrm{1}^{-1}$ (range 3-15 mmol $\cdot 1^{-1}$ ); calcium, $1 \mathrm{mmol} \cdot 1^{-1}$ (range $\left.0.3-2.0 \mathrm{mmol} \cdot 1^{-1}\right)$; and magnesium, $0.8 \mathrm{mmol} \cdot 1^{-1}$ (range $0.2-1.5 \mathrm{mmol} \cdot 1^{-1}$ ) (Criswell et al., 1992; Cunningham, 1997; McCutcheon and Geor, 1998; Sawka and Montain, 2000). Presently, there are no data that make a compelling case for including these electrolytes in fluids consumed during exercise (Powers et al., 1990; Deuster and Singh, 1993; Sawka and Montain, 2000; Sejersted and Sjogaard, 2000).

\section{Intake of other fuels during exercise}

\section{Protein}

Protein ingestion during exercise has theoretical potential to serve both as a fuel for oxidation as well as acting to stimulate cellular responses that have benefits during exercise. At present, there are few data to support any specific recommendations regarding type, amount and timing of protein intake during exercise. However, as discussed by Tipton and Wolfe (2004), protein availability immediately after exercise may stimulate adaptation and, therefore, it may be practical to ingest it during exercise, although it may not be needed during exercise per se. Given that the major pathways for ingested protein to contribute energy for oxidation during prolonged exercise are through deamination and metabolism as carbohydrate and, to a lesser extent, fat, there do not appear to be any advantages of ingesting protein compared with carbohydrate during exercise.

In addition to serving as a fuel, ingested protein from normal foods has the potential to moderate the metabolic responses during exercise under some conditions. For example, as discussed by Burke et al. (2004) and Ivy and colleagues (Zawadzki et al., 1992; Ivy, 2001; Ivy et al., 2002), the addition of small amounts of protein to carbohydrate ingested after exercise augments the plasma insulin response, which has the potential to alter metabolism. However, at present there is insufficient theoretical rationale or data to recommend inclusion of protein in solutions ingested during exercise. A vast number of biologically active substances can be classified as proteins, including those in our common food supply, as well as a seemingly infinite number of herbal supplements as well as manmade substances including drugs. Maughan et al. (2004) discuss the wide range of supplements presently available.

\section{Fat}

Triglyceride stored in adipose tissue and within muscle fibres provides an important endogenous fuel for oxidation during exercise. Because it is not practical to ingest fatty acids during exercise, fat is ingested in the form of either long-chain or medium-chain triglycerides. Ingested long-chain triglycerides are absorbed in the intestines but delivered only slowly into the bloodstream through the lymphatic systems. Typically, long-chain triglycerides begin to enter the blood as chylomicron triglycerides approximately $2 \mathrm{~h}$ after ingestion (Evans et al., 1999) and thus there is no rationale for eating fat during exercise lasting less than $2 \mathrm{~h}$. The extent to which ingested long-chain triglycerides can add to total energy production and performance is not completely clear (Magazanik et al., 1974; Howald and Decombaz, 1983; Blomstrand et al., 1988; Burke and Read, 1989; Davis et al., 1992, 1999, 2000b; Turcotte et al., 1992; MacLean and Graham, 1993; Manore et al., 1993; Schedl et al., 1994; Biolo et al., 1995, 1997; Davis, 1995a,b; Tipton and Wolfe, 1998; Gibala et al., 1999; Rasmussen et al., 2000; Herd et al., 2001; Ivy, 2001; Tipton et al., 2003).

Medium-chain triglycerides are digested rapidly and have theoretical advantages due to the relative ease with which they can pass through cell membranes and enter into oxidative pathways. However, despite extensive study, most investigators (Jeukendrup et al., 1995, 1996; Angus et al., 2000; Horowitz et al., 2000), but not all (van Zyl et al., 1996), have not found them to benefit performance. It would appear that ingestion of sufficiently large does of medium-chain triglycerides causes gastrointestinal distress (Jeukendrup et al., 1996).

\section{Amino acid intake during exercise}

Several amino acids have been theorized (Blomstrand $e t$ al., 1988) to benefit performance when ingested during exercise on the basis of their unknown potential to alter skeletal muscle metabolism or positively influence central nervous system function. However, although their potential is intriguing, especially that of the branched-chain amino acids, studies have not identified a clear benefit to performance or physiological function (MacLean and Graham, 1993; Davis, 1995a,b; Davis et al., 1999, 2000b; Gibala et al., 1999).

\section{Glycerol}

Glycerol is a three-carbon carbohydrate that readily diffuses throughout the body. The main pathway by which glycerol can serve as a fuel is through liver gluconeogenesis and thus a method for maintaining blood glucose availability. In rats, glycerol feeding improves endurance, probably due to the rat's high gluconeogenic ability (Terblanche et al., 1981). In humans, however, glycerol feeding has been found to be ineffective for improving endurance, probably because it has limited potential for maintaining gluconeogenesis (Miller et al., 1983). 
Because ingested glycerol distributes throughout the body water, except for the brain, it has the potential to osmotically increase body water stores and has been advocated as a method for hyperhydration before exercise (Lyons et al., 1990), but does not appear generally effective for improving thermoregulation (Freund et al., 1995; Latzka and Sawka, 2000). There is little reason to suspect that glycerol ingestion during exercise would be beneficial to thermoregulation through retaining more of the ingested fluid in the body, because little fluid is lost in urine during exercise, and this indeed seems to be the case (Murray et al., 1991).

\section{Caffeine}

Unlike other substances that stimulate the central nervous system, caffeine appears to be a socially accepted ergogenic aid and its use is not effectively discouraged within the culture of organized sport. It has long been appreciated that caffeine improves power output, especially during the later stages of endurance performance measured under laboratory conditions (Costill et al., 1978; Ivy et al., 1979; Spriet, 1995). Recently, Cox et al. (2002) have confirmed this performance benefit during prolonged cycling when caffeine is ingested in amounts and at times that have been practised by competitive cyclists for decades (drinking a few hundred millilitres of decarbonated and caffeinated soft drinks). Specifically, a relatively small dose of caffeine (about $1.5 \mathrm{mg} \cdot \mathrm{kg}^{-1}$ or approximately $100 \mathrm{mg}$ ), taken during the last $40 \mathrm{~min}$ of prolonged exercise, was found to improve time-trial performance in laboratory studies. This seems to be the most efficient method for caffeine intake during exercise and it does not appear to be less effective than taking $3-9 \mathrm{mg} \cdot \mathrm{kg}^{-1}$ doses before or throughout prolonged exercise (Cox et al., 2002).

\section{Summary statements with recommendations for fluid and fuel intake during exercise}

1. When possible, fluid should be ingested at rates that most closely match sweating rate. When that is not possible or practical or sufficiently ergogenic, some athletes might tolerate body water losses amounting to $2 \%$ of body weight without significant risk to physical well-being or performance when the environment is cold $\left(5-10^{\circ} \mathrm{C}\right)$ or temperate $\left(21-22^{\circ} \mathrm{C}\right)$. However, when exercising in a hot environment $\left(>30^{\circ} \mathrm{C}\right)$, dehydration by $2 \%$ of body weight impairs absolute power production and predisposes individuals to heat injury. Fluid should not be ingested at rates in excess of sweating rate and thus body water and weight should not increase during exercise

2. During exercise lasting more than $1 \mathrm{~h}$ and which elicits fatigue, athletes are advised to ingest $30-60 \mathrm{~g}$ carbohydrate $\cdot \mathrm{h}^{-1}$, which is rapidly converted to blood glucose, because it generally improves performance. There is no clear physiological need for people to take in fluid or fuel when beginning exercise in a reasonably euhydrated state and proceeding to exercise at low or moderate intensity for less than $1 \mathrm{~h}$ without experiencing undue fatigue or significant dehydration ( $>2 \%$ body weight loss). However, there is no apparent reason for people to avoid fluid and/or carbohydrate according to the guidelines given if this is their preference and it is well tolerated.

3. No benefit is gained by ingesting the following during exercise to justify potential discomfort or costs or potential health risks: glycerol, amino acids, alleged precursors of neurotransmitters claimed to be ergogenic.

4. Sodium should be included in fluids consumed during exercise lasting more than $2 \mathrm{~h}$ or by individuals during any event that stimulates heavy sodium loss (more than 3-4 g of sodium). Although the benefits of drinking fluids containing sodium are not clear during shorter-term exercise (less than $2 \mathrm{~h}$ ) or when sweat loss of sodium is low, there does not appear to be a significant negative effect of drinking solutions containing up to $40 \mathrm{mmol} \cdot \mathrm{1}^{-1}$ sodium. Sodium contained in pills or food is not discouraged, provided it is consumed simultaneously with sufficiently large volumes of fluid.

5. Caffeine intake during the latter stages of prolonged exercise is ergogenic when taken in amounts of $1.5 \mathrm{mg} \cdot \mathrm{kg}^{-1}$.

\section{Acknowledgements}

The author appreciates the advice given by Drs Clyde Williams, Jose Gonzalez-Alonso and Sam Cheuvront, as well as input from Matt Pahnke and Joel Trinity. The author is a member of the Sports Medicine Review Board of the Gatorade Sports Science Institute.

\section{References}

Adolph, E.F. (ed.) (1947). Physiology of Man in the Desert. New York: Interscience.

American College of Sports Medicine (1975). Position statement on the prevention of heat injury during distance running. Medicine and Science in Sports. 
American College of Sports Medicine (1985). Position statement on the prevention of thermal injuries during distance running. Medicine and Science in Sports and Exercise, 17, ix-xiv.

Angus, D.J., Hargreaves, M., Dancey, J. and Febbraio, M.A. (2000). Effect of carbohydrate or carbohydrate plus medium-chain triglyceride ingestion on cycling time trial performance. Fournal of Applied Physiology, 88, 113-119.

Bachle, L., Eckerson, J., Albertson, L., Ebersole, K., Goodwin, J. and Petzel, D. (2001). The effect of fluid replacement on endurance performance. Fournal of Strength and Conditioning Research, 15, 217-224.

Bangsbo, J. (1994). The physiology of soccer - with special reference to intense intermittent exercise. Acta Physiologica Scandinavica, suppl. 619, 1-155.

Bangsbo, J., Norregaard, L. and Thorso, F. (1991). Activity profile of competition soccer. Canadian fournal of Sport Sciences, 16, 110-116.

Barr, S. (1999). Effects of dehydration on exercise performance. Canadian Fournal of Applied Physiology, 24, 164172.

Barr, S. and Costill, D. (1989). Water: can the endurance athlete get too much of a good thing? fournal of the American Dietetic Association, 89, 1629-1632, 1635.

Barr, S., Costill, D. and Fink, W. (1991). Fluid replacement during prolonged exercise: effects of water, saline, or no fluid. Medicine and Science in Sports and Exercise, 23, 811817.

Below, P., Mora-Rodriguez, R., Gonzalez-Alonso, J. and Coyle, E. (1995). Fluid and carbohydrate ingestion independently improve performance during $1 \mathrm{~h}$ of intense exercise. Medicine and Science in Sports and Exercise, 27, 200-210.

Bergstrom, J., Hermansen, L., Hultman, E. and Saltin, B. (1967). Diet, muscle glycogen and physical performance. Acta Physiologica Scandinavica, 71, 140-150.

Biolo, G., Maggi, S.P., Williams, B.D., Tipton, K.D. and Wolfe, R.R. (1995). Increased rates of muscle protein turnover and amino acid transport after resistance exercise in humans. American fournal of Physiology, 268, E514-E520.

Biolo, G., Tipton, K., Klein, S. and Wolfe, R. (1997). An abundant supply of amino acids enhances the metabolic effect of exercise on muscle protein. American fournal of Physiology, 273, E122-E129.

Blomstrand, E., Celsing, F. and Newsholme, E. (1988). Changes in plasma concentrations of aromatic and branched-chain amino acids during sustained exercise in man and their possible role in fatigue. Acta Physiologica Scandinavica, 133, 115-121.

Brown, A.H. (1947). Relative influences of heat, work, and dehydration on blood circulation. In Physiology of Man in the Desert (edited by E.F. Adolph), pp. 197-207. New York: Interscience.

Burke, L. and Read, R. (1989). Sports nutrition: approaching the nineties. Sports Medicine, 8, 80-100.

Burke, L.M., Kiens, B. and Ivy, J.L. (2004). Carbohydrates and fat for training and recovery. Fournal of Sports Sciences, 22, 15-30.
Casa, D.J. (2000). National athletic trainer's association position statement: fluid replacement for athletes. Fournal of Athletic Training, 35, 212-224.

Cheuvront, S.S.M. (2001). Physical exercise and exhaustion from heat strain. Fournal of the Korean Society of Living Environmental Systems, 8, 134-145.

Cheuvront, S. and Haymes, E. (2001). Thermoregulation and marathon running: biological and environmental influences. Sports Medicine, 31, 743-762.

Cheuvront, S., Carter, R. and Sawka, M.N. (2003). Fluid balance and endurance exercise performance. Current Sports Medicine Reports, 2, 202-208.

Coggan, A.R. and Coyle, E.F. (1988). Effect of carbohydrate feedings during high-intensity exercise. Fournal of Applied Physiology, 65, 1703-1737.

Coggan, A. and Coyle, E. (1991). Carbohydrate ingestion during prolonged exercise: effects on metabolism and performance. Exercise and Sport Science Reviews, 19, 1-40.

Convertino, V., Armstrong, L., Coyle, E., Mack, G., Sawka, M., Senay, L. and Sherman, W. (1996). American College of Sports Medicine position stand: exercise and fluid replacement. Medicine and Science in Sports and Exercise, 28, i-vii.

Costill, D.L. (1972). Physiology of marathon running. Fournal of the American Medical Association, 221, 10241029.

Costill, D. and Miller, J. (1980). Nutrition for endurance sport: carbohydrate and fluid balance. International fournal of Sports Medicine, 1, 2-14.

Costill, D., Dalsky, G. and Fink, W. (1978). Effects of caffeine ingestion on metabolism and exercise performance. Medicine and Science in Sports, 10, 155-158.

Cox, G.R., Desbrow, B., Montgomery, P.G., Anderson, M.E., Bruce, C.R., Macrides, T.A., Martin, D.T., Moquin, A., Roberts, A., Hawley, J.A. and Burke, L.M. (2002). Effect of different protocols of caffeine intake on metabolism and endurance performance. Fournal of Applied Physiology, 93, 990-999.

Coyle, E.F. and Montain, S.J. (1992a). Benefits of fluid replacement with carbohydrate during exercise. Medicine and Science in Sports and Exercise, 24, S324-S330.

Coyle, E.F. and Montain, S.J. (1992b). Carbohydrate and fluid ingestion during exercise: are there trade-offs? Medicine and Science in Sports and Exercise, 24, 671-678.

Coyle, E., Costill, D., Fink, W. and Hoopes, D. (1978). Gastric emptying rates for selected athletic drinks. Research Quarterly, 49, 119-124.

Coyle, E.F., Coggan, A.R., Hemmert, M.K. and Ivy, J.L. (1986). Muscle glycogen utilization during prolonged strenuous exercise when fed carbohydrate. Fournal of Applied Physiology, 61, 165-172.

Criswell, D., Renshler, K., Powers, S., Tulley, R., Cicale, M. and Wheeler, K. (1992). Fluid replacement beverages and maintenance of plasma volume during exercise: role of aldosterone and vasopressin. European fournal of Applied Physiology, 65, 445-451.

Cunningham, J. (1997). Is potassium needed in sports drinks for fluid replacement during exercise? International fournal of Sport Nutrition, 7, 154-159. 
Davis, J. (1995a). Carbohydrates, branched-chain amino acids, and endurance: the central fatigue hypothesis. International fournal of Sport Nutrition, 5(suppl.), S29-S38.

Davis, J. (1995b). Central and peripheral factors in fatigue. Fournal of Sports Sciences, 13 (special issue), S49-S53.

Davis, J., Bailey, S., Woods, J., Galiano, F., Hamilton, M. and Bartoli, W. (1992). Effects of carbohydrate feedings on plasma free tryptophan and branched-chain amino acids during prolonged cycling. European fournal of Applied Physiology, 65, 513-519.

Davis, J.M., Jackson, D.A., Broadwell, M.S., Queary, J.L. and Lambert, C.L. (1997). Carbohydrate drinks delay fatigue during intermittent, high-intensity cycling in active men and women. International fournal of Sport Nutrition, 7, 261-273.

Davis, J., Welsh, R., De Volve, K. and Alderson, N. (1999). Effects of branched-chain amino acids and carbohydrate on fatigue during intermittent, high-intensity running. International Fournal of Sports Medicine, 20, 309-314.

Davis, J., Welsh, R. and Alerson, N. (2000a). Effects of carbohydrate and chromium ingestion during intermittent high-intensity exercise to fatigue. International fournal of Sport Nutrition and Exercise Metabolism, 10, 476-485.

Davis, J.M., Alderson, N.L. and Welsh, R.S. (2000b). Serotonin and central nervous system fatigue: nutritional considerations. American Fournal of Clinical Nutrition, 72, 573S-578S.

Deuster, P.A. and Singh, A. (1993). Responses of plasma magnesium and other cations to fluid replacement during exercise. Fournal of the American College of Nutrition, 12, 286-293.

Eichner, E. (1998). Treatment of suspected heat illness. International fournal of Sports Medicine, 19(suppl. 2), S150 S153.

Evans, K., Clark, M.L. and Frayn, K.N. (1999). Effects of an oral and intravenous fat load on adipose tissue and forearm lipid metabolism. American fournal of Physiology, 276, E241-E248.

Fallowfield, J.L., Williams, C., Booth, J., Choo, B.H. and Growns, S. (1996). Effect of water ingestion on endurance capacity during prolonged running. Fournal of Sports Sciences, 14, 497-502.

Febbraio, M., Murton, P., Selig, S., Clark, S., Lambert, D., Angus, D. and Carey, M. (1996a). Effect of CHO ingestion on exercise metabolism and performance in different ambient temperatures. Medicine and Science in Sports and Exercise, 28, 1380-1387.

Febbraio, M.A., Carey, M.F., Snow, R.J., Stathis, C.G. and Hargreaves, M. (1996b). Influence of elevated muscle temperature on metabolism during intense, dynamic exercise. American foumal of Physiology, 271, R1251R1255.

Freund, B.J., Montain, S.J., Young, A.J., Sawka, M.N., DeLuca, J.P., Pandolf, K.B. and Valeri, C.R. (1995). Glycerol hyperhydration: hormonal, renal, and vascular fluid responses. Fournal of Applied Physiology, 79, 2069-2077.
Fritzsche, R.G., Switzer, T.W., Hodgkinson, B.J., Lee, S.H., Martin, J.C. and Coyle, E.F. (2000). Water and carbohydrate ingestion during prolonged exercise increase maximal neuromuscular power. Fournal of Applied Physiology, 88, 730-737.

Galloway, S. and Maughan, R. (1998). The effects of substrate and fluid provision on thermoregulatory, cardiorespiratory and metabolic responses to prolonged exercise in a cold environment in man. Experimental Physiology, 83, 419-430.

Galloway, S. and Maughan, R. (2000). The effects of substrate and fluid provision on thermoregulatory and metabolic responses to prolonged exercise in a hot environment. Fournal of Sports Sciences, 18, 339-351.

Gibala, M.J., Lozej, M., Tarnopolsky, M.A., McLean, C. and Graham, T.E. (1999). Low glycogen and branchedchain amino acid ingestion do not impair anaplerosis during exercise in humans. Fournal of Applied Physiology, 87, 1662-1667.

Gonzalez-Alonso, J. (1998). Separate and combined influences of dehydration and hyperthermia on cardiovascular responses to exercise. International foumal of Sports Medicine, 19(suppl. 2), S111-S114.

Gonzalez-Alonso, J. and Calbet, J.A.L. (2003). Reductions in systemic and skeletal muscle blood flow and oxygen delivery limit maximal aerobic capacity in humans. Circulation, 107, 824-830.

Gonzalez-Alonso, J., Mora-Rodriguez, R., Below, P.R. and Coyle, E.F. (1995). Dehydration reduces cardiac output and increases systemic and cutaneous vascular resistance during exercise. Fournal of Applied Physiology, 79, 14871496.

Gonzalez-Alonso, J., Mora-Rodriguez, R., Below, P.R. and Coyle, E.F. (1997). Dehydration markedly impairs cardiovascular function in hyperthermic endurance athletes during exercise. Fournal of Applied Physiology, 82, 12291236.

Gonzalez-Alonso, J., Calbet, J.A.L. and Nielsen, B. (1998). Muscle blood flow is reduced with dehydration during prolonged exercise in humans. Fournal of Physiology, 513, 895-905.

Gonzalez-Alonso, J., Calbet, J.A. and Nielsen, B. (1999a). Metabolic and thermodynamic responses to dehydrationinduced reductions in muscle blood flow in exercising humans. Fournal of Physiology, 520, 577-589.

Gonzalez-Alonso, J., Teller, C., Andersen, S.L., Jensen, F.B., Hyldig, T. and Nielsen, B. (1999b). Influence of body temperature on the development of fatigue during prolonged exercise in the heat. Fournal of Applied Physiology, 86, 1032-1039.

Gonzalez-Alonso, J., Mora-Rodriguez, R. and Coyle, E.F. (2000). Stroke volume during exercise: interaction of environment and hydration. American fournal of Physiology, 278, H321-H330.

Hargreaves, M. (1996). Carbohydrates and exercise performance. Nutrition Reviews, 54, S136-S139. 
Hargreaves, M., Costill, D., Burke, L., McConell, G. and Febbraio, M. (1994). Influence of sodium on glucose bioavailability during exercise. Medicine and Science in Sports and Exercise, 26, 365-368.

Hargreaves, M., Dillo, P., Angus, D. and Febbraio, M. (1996). Effect of fluid ingestion on muscle metabolism during prolonged exercise. Fournal of Applied Physiology, 80, 363-366.

Herd, S., Kiens, B., Boobis, L. and Hardman, A. (2001). Moderate exercise, postprandial lipemia, and skeletal muscle lipoprotein lipase activity. Metabolism, 50, 756-762.

Horowitz, J.F., Mora-Rodriguez, R., Byerley, L.O. and Coyle, E.F. (2000). Preexercise medium-chain triglyceride ingestion does not alter muscle glycogen use during exercise. Fournal of Applied Physiology, 88, 219-225.

Howald, H. and Decombaz, J. (1983). Nutrient intake and energy regulation in physical exercise. Experientia, 44(suppl.), 77-88.

Hubbard, R.W., Sandick, B.L., Matthew, W.T., Francesconi, R.P., Sampson, J.B., Durkot, M.J., Maller, O. and Engell, D.B. (1984). Voluntary dehydration and alliesthesia for water. Fournal of Applied Physiology, 57, 868-873.

Ivy, J. (2001). Dietary strategies to promote glycogen synthesis after exercise. Canadian fournal of Applied Physiology, 26(suppl.), S236-S245.

Ivy, J., Costill, D., Fink, W. and Lower, R. (1979). Influence of caffeine and carbohydrate feedings on endurance performance. Medicine and Science in Sports, 11, 6-11.

Ivy, J.L., Goforth, H.W., Jr., Damon, B.M., McCauley, T.R., Parsons, E.C. and Price, T.B. (2002). Early postexercise muscle glycogen recovery is enhanced with a carbohydrate-protein supplement. Fournal of Applied Physiology, 93, 1337-1344.

Jeukendrup, A.E., Saris, W.H., Schrauwen, P., Brouns, F. and Wagenmakers, A.J. (1995). Metabolic availability of medium-chain triglycerides coingested with carbohydrates during prolonged exercise. Fournal of Applied Physiology, 79, 756-762.

Jeukendrup, A., Saris, W., Brouns, F., Halliday, D. and Wagenmakers, J. (1996). Effects of carbohydrate (CHO) and fat supplementation on $\mathrm{CHO}$ metabolism during prolonged exercise. Metabolism, 45, 915-921.

Ladell, W. (1955). The effects of water and salt intake upon the performance of men working in hot and humid environments. Fournal of Physiology, 127, 11-26.

Latzka, W. and Sawka, M. (2000). Hyperhydration and glycerol: thermoregulatory effects during exercise in hot climates. Canadian fournal of Applied Physiology, 25, 536545.

Lyons, T., Riedesel, M., Meuli, L. and Chick, T. (1990). Effects of glycerol-induced hyperhydration prior to exercise in the heat on sweating and core temperature. Medicine and Science in Sports and Exercise, 22, 477-483.

MacLean, D.A. and Graham, T.E. (1993). Branched-chain amino acid supplementation augments plasma ammonia responses during exercise in humans. Fournal of Applied Physiology, 74, 2711-2717.

Magazanik, A., Shapiro, Y., Meytes, D. and Meytes, I. (1974). Enzyme blood levels and water balance during a marathon race. Fournal of Applied Physiology, 36, 214-217.
Manore, M., Thompson, J. and Russo, M. (1993). Diet and exercise strategies of a world-class bodybuilder. International Fournal of Sport Nutrition, 3, 76-86.

Maron, M.B., Wagner, J.A. and Horvath, S.M. (1977). Thermoregulatory responses during competitive marathon running. Fournal of Applied Physiology, 42, 909-914.

Maughan, R.J. (1984). Temperature regulation during marathon competition. British fournal of Sports Medicine, 18, 257-260.

Maughan, R.J. (1985). Thermoregulation in marathon competition at low ambient temperature. International Fournal of Sports Medicine, 6, 15-19.

Maughan, R.J. (1991). Fluid and electrolyte loss and replacement in exercise. Fournal of Sports Sciences, $\mathbf{9}$ (special issue), 117-142.

Maughan, R.J. and Leiper, J.B. (1994). Fluid replacement requirements in soccer. Fournal of Sports Sciences, 12 (special issue), S29-S34.

Maughan, R.J. and Noakes, T.D. (1991). Fluid replacement and exercise stress: a brief review of studies on fluid replacement and some guidelines for the athlete. Sports Medicine, 12, 16-31.

Maughan, R.J., Goodburn, R., Griffin, J., Irani, M., Kirwan, J., Leiper, J., MacLaren, D., McLatchie, G., Tsintsas, K. and Williams, C. (1993). Fluid replacement in sport and exercise - a consensus statement. British fournal of Sports Medicine, 27, 34-35.

Maughan, R.J., King, D.S. and Lea, T. (2004). Dietary supplements. Fournal of Sports Sciences, 22, 95-113.

McConell, G., Burge, C., Skinner, S. and Hargreaves, M. (1997). Influence of ingested fluid volume on physiological responses during prolonged exercise. Acta Physiologica Scandinavica, 160, 149-156.

McConell, G., Stephens, T. and Canny, B. (1999). Fluid ingestion does not influence intense 1 -h exercise performance in a mild environment. Medicine and Science in Sports and Exercise, 31, 386-392.

McCutcheon, L. and Geor, R. (1998). Sweating: fluid and ion losses and replacement. Veterinary Clinics of North America Equine Practice, 14, 75-95.

McGregor, S., Nicholas, C., Lakomy, H. and Williams, C. (1999). The influence of intermittent high-intensity shuttle running and fluid ingestion on the performance of a soccer skill. Fournal of Sports Sciences, 17, 895-903.

Millard-Stafford, M. (1992). Fluid replacement during exercise in the heat: review and recommendations. Sports Medicine, 13, 223-233.

Millard-Stafford, M., Sparling, P., Rosskopf, L., Snow, T., DiCarlo, L. and Hinson, B. (1995). Fluid intake in male and female runners during a $40-\mathrm{km}$ field run in the heat. Fournal of Sports Sciences, 13, 257-263.

Millard-Stafford, M., Rosskopf, L., Snow, T. and Hinson, B. (1997). Water versus carbohydrate-electrolyte ingestion before and during a $15-\mathrm{km}$ run in the heat. International Fournal of Sport Nutrition, 7, 26-38.

Miller, J., Coyle, E., Sherman, W., Hagberg, J., Costill, D., Fink, W., Terblanche, S. and Holloszy, J. (1983). Effect of glycerol feeding on endurance and metabolism during prolonged exercise in man. Medicine and Science in Sports and Exercise, 15, 237-242. 
Mitchell, J.B., Costill, D.L., Houmard, J.A., Fink, W.J., Pascoe, D.D. and Pearson, D.R. (1989). Influence of carbohydrate dosage on exercise performance and glycogen metabolism. Fournal of Applied Physiology, 67, 1843-1849.

Montain, S.J. and Coyle, E.F. (1992). Influence of graded dehydration on hyperthermia and cardiovascular drift during exercise. Fournal of Applied Physiology, 73, 13401350.

Montain, S.J. and Coyle, E.F. (1993). Influence of the timing of fluid ingestion on temperature regulation during exercise. Fournal of Applied Physiology, 75, 688-695.

Montain, S., Sawka, M. and Wenger, C. (2001). Hyponatremia associated with exercise: risk factors and pathogenesis. Exercise and Sport Science Reviews, 29, 113-117.

Murray, R., Eddy, D., Murray, T., Seifert, J., Paul, G. and Halaby, G. (1987). The effect of fluid and carbohydrate feedings during intermittent cycling exercise. Medicine and Science in Sports and Exercise, 19, 597-604.

Murray, R., Paul, G., Seifert, J., Eddy, D. and Halaby, G. (1989). The effects of glucose, fructose, and sucrose ingestion during exercise. Medicine and Science in Sports and Exercise, 21, 275-282.

Murray, R., Eddy, D.E., Paul, G.L., Seifert, J.G. and Halaby, G.A. (1991). Physiological responses to glycerol ingestion during exercise. Fournal of Applied Physiology, 71, 144-149.

Nicholas, C., Williams, C., Lakomy, H., Phillips, G. and Nowitz, A. (1995). Influence of ingesting a carbohydrateelectrolyte solution on endurance capacity during intermittent, high-intensity shuttle running. Fournal of Sports Sciences, 13, 283-290.

Nicholas, C., Tsintzas, K., Boobis, L. and Williams, C. (1999). Carbohydrate-electrolyte ingestion during intermittent high-intensity running. Medicine and Science in Sports and Exercise, 31, 1280-1286.

Nicholas, C., Nuttall, F. and Williams, C. (2000). The Loughborough Intermittent Shuttle Test: a field test that simulates the activity pattern of soccer. Fournal of Sports Sciences, 18, 97-104.

Nielsen, B. and Nybo, L. (2003). Cerebral changes during exercise in the heat. Sports Medicine, 33, 1-11.

Nielsen, B., Hyldig, T., Bidstrup, F., Gonzalez-Alonso, J. and Christoffersen, G. (2001). Brain activity and fatigue during prolonged exercise in the heat. Pflügers Archive, 442, 41-48.

Noakes, T.D. (2003). Overconsumption of fluids by athletes. British Medical fournal, 327, 113-114.

Noakes, T. and Martin, D. (2002). IMMDA-AIMS advisory statement on guidelines for fluid replacement during marathon running. New Studies in Athletics, 17, 15-24.

Noakes, T., Goodwin, N., Rayner, B., Branken, T. and Taylor, R. (1985). Water intoxication: a possible complication during endurance exercise. Medicine and Science in Sports and Exercise, 17, 370-375.

Noakes, T., Myburgh, K., du Plessis, J., Lang, L., Lambert, M., van der Riet, C. and Schall, R. (1991a). Metabolic rate, not percent dehydration, predicts rectal temperature in marathon runners. Medicine and Science in Sports and Exercise, 23, 443-449.
Noakes, T., Rehrer, N. and Maughan, R. (1991b). The importance of volume in regulating gastric emptying. Medicine and Science in Sports and Exercise, 23, 307-313.

O'Brien, K., Montain, S., Corr, W., Sawka, M., Knapik, J. and Craig, S. (2001). Hyponatremia associated with overhydration in U.S. Army trainees. Military Medicine, 166, 405-410.

Pitts, G.J. and Consolazio, F.C. (1944). Work in the heat as affected by intake of water, salt and glucose. American Fournal of Physiology, 142, 253-259.

Powers, S., Lawler, J., Dodd, S., Tulley, R., Landry, G. and Wheeler, K. (1990). Fluid replacement drinks during high intensity exercise: effects on minimizing exercise-induced disturbances in homeostasis. European fournal of Applied Physiology, 60, 54-60.

Pugh, L.G., Corbett, J.L. and Johnson, R.H. (1967). Rectal temperatures, weight losses, and sweat rates in marathon running. Fournal of Applied Physiology, 23, 347-352.

Rasmussen, B.B., Tipton, K.D., Miller, S.L., Wolf, S.E. and Wolfe, R.R. (2000). An oral essential amino acidcarbohydrate supplement enhances muscle protein anabolism after resistance exercise. Fournal of Applied Physiology, 88, 386-392.

Rehrer, N. (1994). The maintenance of fluid balance during exercise. International Fournal of Sports Medicine, 15, 122125.

Rehrer, N. (2001). Fluid and electrolyte balance in ultraendurance sport. Sports Medicine, 31, 701-715.

Rehrer, N.J., Wagenmakers, A.J., Beckers, E.J., Halliday, D., Leiper, J.B., Brouns, F., Maughan, R.J., Westerterp, K. and Saris, W.H. (1992). Gastric emptying, absorption, and carbohydrate oxidation during prolonged exercise. Fournal of Applied Physiology, 72, 468-475.

Rehrer, N., Beckers, E., Brouns, F., Saris, W. and ten Hoor, F. (1993). Effects of electrolytes in carbohydrate beverages on gastric emptying and secretion. Medicine and Science in Sports and Exercise, 25, 42-51.

Robinson, T., Hawley, J., Palmer, G., Wilson, G., Gray, D., Noakes, T. and Dennis, S. (1995). Water ingestion does not improve 1-h cycling performance in moderate ambient temperatures. European fournal of Applied Physiology, 71, 153-160.

Sawka, M. and Coyle, E. (1999). Influence of body water and blood volume on thermoregulation and exercise performance in the heat. Exercise and Sport Science Reviews, 27, 167-218.

Sawka, M.N. and Montain, S.J. (2000). Fluid and electrolyte supplementation for exercise heat stress. American fournal of Clinical Nutrition, 72, 564S-572S.

Sawka, M.N., Montain, S.J. and Latzka, W.A. (2001). Hydration effects on thermoregulation and performance in the heat. Comparative Biochemistry and Physiology A: Molecular and Integrative Physiology, 128, 679-690.

Schedl, H., Maughan, R. and Gisolfi, C. (1994). Intestinal absorption during rest and exercise: implications for formulating an oral rehydration solution (ORS). Proceedings of a roundtable discussion, 21-22 April 1993. Medicine and Science in Sports and Exercise, 26, 267-280. 
Sejersted, O.M. and Sjogaard, G. (2000). Dynamics and consequences of potassium shifts in skeletal muscle and heart during exercise. Physiological Reviews, 80, 14111481.

Speedy, D., Noakes, T., Boswell, T., Thompson, J., Rehrer, N. and Boswell, D. (2001). Response to a fluid load in athletes with a history of exercise induced hyponatremia. Medicine and Science in Sports and Exercise, 33, 1434-1442.

Spriet, L.L. (1995). Caffeine and performance. International Fournal of Sport Nutrition, 5(suppl.), S84-S99.

Sugiura, K. and Kobayashi, K. (1998). Effect of carbohydrate ingestion on sprint performance following continuous and intermittent exercise. Medicine and Science in Sports and Exercise, 30, 1624-1630.

Terblanche, S.E., Fell, R.D., Juhlin-Dannfelt, A.C., Craig, B.W. and Holloszy, J.O. (1981). Effects of glycerol feeding before and after exhausting exercise in rats. Fournal of Applied Physiology, 50, 94-101.

Tipton, K. and Wolfe, R. (1998). Exercise-induced changes in protein metabolism. Acta Physiologica Scandinavica, 162, 377-387.

Tipton, K.D. and Wolfe, R.R. (2004). Protein and amino acids for athletes. Fournal of Sports Sciences, 22, 65-79.

Tipton, K.D., Borsheim, E., Wolf, S.E., Sanford, A.P. and Wolfe, R.R. (2003). Acute response of net muscle protein balance reflects 24-h balance after exercise and amino acid ingestion. American fournal of Physiology, 284, E76-E89.

Turcotte, L.P., Richter, E.A. and Kiens, B. (1992). Increased plasma FFA uptake and oxidation during prolonged exercise in trained vs untrained humans. American fournal of Physiology, 262, E791-E799.

van Zyl, C.G., Lambert, E.V., Hawley, J.A., Noakes, T.D. and Dennis, S.C. (1996). Effects of medium-chain triglyceride ingestion on fuel metabolism and cycling performance. Fournal of Applied Physiology, 80, 2217-2225.
Vrijens, D.M.J. and Rehrer, N.J. (1999). Sodium-free fluid ingestion decreases plasma sodium during exercise in the heat. Fournal of Applied Physiology, 86, 1847-1851.

Wagenmakers, A.J., Brouns, F., Saris, W.H. and Halliday, D. (1993). Oxidation rates of orally ingested carbohydrates during prolonged exercise in men. Fournal of Applied Physiology, 75, 2774-2780.

Walsh, R., Noakes, T., Hawley, J. and Dennis, S. (1994). Impaired high-intensity cycling performance time at low levels of dehydration. International fournal of Sports Medicine, 15, 392-398.

Welsh, R., Davis, J., Burke, J. and Williams, H. (2002). Carbohydrates and physical/mental performance during intermittent exercise to fatigue. Medicine and Science in Sports and Exercise, 34, 723-731.

Wemple, R., Morocco, T. and Mack, G. (1997). Influence of sodium replacement on fluid ingestion following exercise-induced dehydration. International fournal of Sport Nutrition, 7, 104-116.

Wilk, B. and Bar-Or, O. (1996). Effect of drink flavor and $\mathrm{NaCl}$ on voluntary drinking and hydration in boys exercising in the heat. Fournal of Applied Physiology, 80, 1112-1117.

Wyndham, C. and Strydom, N. (1969). The danger of an inadequate water intake during marathon running. South African Medical fournal, 43, 893-896.

Zawadzki, K.M., Yaspelkis, B.B., III and Ivy, J.L. (1992). Carbohydrate-protein complex increases the rate of muscle glycogen storage after exercise. Fournal of Applied Physiology, 72, 1854-1859. 